\title{
RELATION OF DIETARY FACTORS WITH INFECTION AND MORTALITY RATES OF COVID-19 ACROSS THE WORLD
}

\author{
D.M. ABDULAH ${ }^{1}$, A.B. HASSAN ${ }^{2}$ \\ 1. Community Health Unit, College of Nursing, University of Duhok, Iraq; 2. Basic Sciences Department, College of Nursing, University of Duhok, Iraq. \\ Corresponding author: Deldar Morad Abdulah, Community Health Unit, College of Nursing, University of Duhok, Iraq, Email: deldarmorad@gmail.com, Phone: +9647507443319, \\ ORCID: https://orcid.org/0000-0002-8986-5793
}

\begin{abstract}
Objective: Poor dietary habits are considered to be the second-leading risk factors for mortality and disability-adjusted life-years (DALYs) in the world. Dietary patterns are different based on cultural, environmental, technological, and economic factors. Nutritional deficiencies of energy, protein, and specific micronutrients have been shown to contribute to depressed immune function and increased susceptibility to infections. We aimed to explore the relation of dietary factors with global infection and mortality rates of COVID-19 in this study. Design: In the current ecological study, the countries that had national dietary data from the Global Dietary Databases of the United Nations and coronavirus disease statistics from the World Health Organization (WHO) were included. The countries that had coronavirus disease statistics from the WHO were consecutively checked for the recent data of the dietary factors. Setting: World. Participants: 158 countries across the world. Measurements: infection and mortality rates of COVID-19; dietary factors. Results: The median crude infection and mortality rates by COVID-19 were 87.78 (IQR: 468.03) and 0.0015 (IQR: $0.0059)$, respectively. The two highest percentage of the crude infection rate were between 0 and $500(75.9 \%)$ and 500-1000 (8.9\%) per one million persons. The regression analysis showed that the crude infection rate has been increased by raising consuming fruits (Beta: 0.237; $\mathrm{P}=0.006$ ) and calcium (Beta: 0.286; $\mathrm{P}=0.007$ ) and was decreased with rising consuming beans and legumes (Beta: $-0.145 ; \mathrm{P}=0.038$ ). The analysis showed that the crude mortality rate was increased by raising consuming sugar-sweetened beverages (Beta: $0.340 ; \mathrm{P}<0.001$ ). Whereas, the crude mortality rate by COVID-19 has been decreased by increasing fruits consuming (Beta: -0.226 ; $\mathrm{P}=0.047$ ) and beans and legumes (Beta: $-0.176 ; \mathrm{P}=0.046$ ). Conclusion: The present study showed the higher intake of fruits and sugar-sweetened beverages had a positive effect on infection and mortally rates by COVID19 , respectively. In contrast, the higher intake of beans and legumes had a negative effect on both increasing infection and mortality rates.
\end{abstract}

Key words: Dietary Factors, acute respiratory infections, macronutrients, proteins, fruits.

Abbreviations: DALYs: disability-adjusted life-years; IFN: Interferon; IQR: Interquartile Range; RNA: RiboNucleic Acid; SPSS: statistical package for social sciences; SSBs: sugar-sweetened beverages; WHO: World Health Organization.

\section{Introduction}

Poor dietary habits are considered to be the second-leading risk factors for mortality and disability-adjusted life-years (DALYs) in the world. The poor dietary habits are responsible for 10.3 million deaths and 229.1 million DALYs in 2016 (1). For example, the following dietary habits are among the leading risk factors for early death and disability in European countries. The habits are low intakes of whole grains, fruit and vegetables, and nuts and seeds, and high intakes of alcohol and sodium. The western dietary habits are consuming diet processed, high in red and processed meat, diets with high in sugar-sweetened beverages, and low in milk. These kinds of dietary habits are regarded to be a rising health concern.

Dietary patterns are different based on cultural, environmental, technological, and economic factors. However, the Dietary patterns are becoming similar due to increasing living standards and growing globalization of the food sector $(2,3)$.

Mertens et al. (4) explored the dietary intakes in four different European counters using individual-level dietary Received May 8, 2020

Accepted for publication May 26, 2020 intake in adults in nationally- representative surveys of Denmark, France, Czech Republic, and Italy. They reported a higher intake of fruits and vegetables and lower intakes of sweetened beverages and alcohol in Italy. While individuals in Denmark and the Czech Republic had a higher intake of vegetables. A comparison of population subgroups within countries shows that there is a difference in the dietary preferences, beliefs, and practices for particular consumer groups. For example, highly-educated persons and women have a higher intake of fish, nuts, and seeds along with lower intake of red and processed meats (5).

The individual-level reported dietary data of the countries could be used as a useful tool to make a connection between health and environment with foods as their common denominator (1). A recent review study reported that the detailed assessment of patients for the dietary and nutritional risks along with medical, lifestyle, and environmental factors with suitable risk management strategies make the sensible way to deal with the COVID-19 (6). The diet and nutrition have a variance impact on the immune system competence. In addition, they determine the risk and severity of the 1011
Published online July 4, 2020, http://10.1007/s12603-020-1434-0 


\section{DIETARY FACTORS IN COVID-19}

infections. The relation between diet, nutrition, infection, and immunity is bidirectional (7). The macro-, micronutrients, and phytonutrients in diet, such as fruits and colorful vegetables improve healthy immune responses. The microand phytonutrients provide the antioxidants and the antiinflammatory nutrients, like beta-carotene, vitamin $\mathrm{C}$, vitamin $\mathrm{E}$, and polyphenolic compounds resulting in modulating the immune functions $(8,9)$.

Nutritional deficiencies of energy, protein, and specific micronutrients have been shown to contribute to depressed immune function and increased susceptibility to infections. The sufficient intake of iron, zinc, and vitamins A, E, B6, and B12 is vital for the overall maintenance of immune function (10).

The new epidemics of Coronavirus Disease 2019 (COVID19) has become a pandemic to the world currently. We make a hypothesis that geographical variation in dietary factors could have a role in infection and mortality rates of COVID-19 in the world. Therefore, we aimed to explore the relation of dietary factors with global infection and mortality rates of COVIS-19 in this study.

\section{Subjects and Methods}

\section{Study design and sampling}

In the current ecological study, the countries that had national dietary data from the Global Dietary Databases of the United Nations (11) and coronavirus disease statistics from the World Health Organization (WHO) were included (12). The countries that had coronavirus disease statistics from the WHO were consecutively checked for the recent data of the dietary factors.

\section{Inclusions and exclusion criteria}

The countries/states met eligibility criteria for this investigation if they had the statistics from the WHO Coronavirus disease (COVID-19) situation dashboard from the website of the World Health Organization by 24 April 2020 (12). The following countries were excluded from the analysis due to not having the statistics of the COVID-19; Comoros, North Korea, Kiribati, Lesotho, Malawi, Marshall Islands, Micronesia, Nauru, Palau, Samoa, Sao Tome, and Principe, Solomon Islands, South Sudan, Tajikistan, Tonga, Turkmenistan, Tuvalu, Vanuatu, and Yemen.

The following countries were excluded from the study due to not having data on the national dietary factors on the website of the Global Dietary Database (11). The countries were the Central African Republic; Democratic Republic of the Congo; Comoros; Djibouti; Dominica; Federated State of Micronesia; Gabon; Kiribati; Lebanon; Liberia; Lesotho; Republic of Moldova; Marshall Islands; Malawi; State of Palestine; Russian Federation; Solomon Islands; South Sudan; Sao Tome and Principe; Syria; Tajikistan; Turkmenistan; Tonga; Vanuatu; Samoa; and Yemen. The available draft estimates of currently available for a set of dietary factors in GDD 2015 was used for this study. The following dietary factors were included; Fruits $(\mathrm{g} / \mathrm{d})$, Non-starchy vegetables $(\mathrm{g} / \mathrm{d})$, Beans and legumes $(\mathrm{g} / \mathrm{d})$, Nuts and seeds $(\mathrm{g} / \mathrm{d})$, Unprocessed red meats $(\mathrm{g} / \mathrm{d})$, Sugarsweetened beverages $(\mathrm{g} / \mathrm{d})$, Fruit juices $(\mathrm{g} / \mathrm{d})$, Total protein (g/d), Calcium (mg/d), Potassium (mg/d), and Total milk (g/d).

The populations of the countries were extracted from the United Nations Statistics Division (13). The estimated populations of the year 2018 were considered for the countries. Some of the countries had not the population for the year 2018. Therefore, the authors checked for the years 2015, 2016, and 2017. Accordingly, the population of 2017 was used for the following country; Algeria.

The population of 2015 was considered for the following countries: Lybia; Sierra Leone. The population of 2016 was extracted for the following countries: Mali; Mauritania; Papua New Guinea; Sudan and 2017 for the following countries; Bhutan; Bosni; Burkina Faso; Fiji; Guyana; Niger; Nigeria; Pakistan; UAE.

The populations of the following countries were not available for the 2015-2019 period. Therefore, the population of the following countries was not included in this study based on the eligibility criteria. These countries were the Central African Republic; Djibouti; Djibouti; Dominica; Gabon; Kosovo; Lebanon; Liberia; Moldova; Russia; Saint Kitts and Nevis; Syria; Somalia, the Democratic Republic of the Cong. Finally, 158 countries/states were included in this study.

\section{Statistical analyses}

The general characteristics of the countries were presented in median (Interquartile Range [IQR], mean (Std. Deviation), and number (Percentage). The confirmed and dead cases were presented in median and interquartile range due to the nonnormal distribution of the data. The normality of the outcomes was examined in drawing a histogram and Box plot. The number of confirmed cases was divided by the total population of a country multiplied by 1000,000 to obtain the infection rate of COVID-19 per one million persons. The number of dead cases was divided by the total number of confirmed cases and divided by total population multiplied by 1000,000 to obtain the mortality rate/1000,000 persons.. The infection and mortality rates were determined in a median and interquartile range following dealing with the potential outliers. The upper limit values were considered for the extremely higher limit values in the infection and mortality rates. The crude infection rate was categorized into the following groups; 0-500; 500-1000; 1000-1500; 1500-2000; 2000-2500; and > 2500 per one million person.

The infection and mortality rates were transformed through the Ln technique to obtain a normally distributed histogram. Following that, the correlation of transformed infection and mortality rates of the COVID-19 with dietary factors in the world was performed in Pearson Correlation. The Matrix Scatter Plots were uses to make the scatter plots for the correlation of infection and mortality rates with dietary factors. The role of dietary factors in the infection and mortality rates 
Table 1

Crude infection and mortality rates of COVID-19 in the world

\begin{tabular}{|c|c|c|c|}
\hline Infection and mortality rates $/ 1000,000$ persons & Range & Median & Interquartile Range \\
\hline Crude infection rate & $0.00-24034.51$ & 87.78 & 468.03 \\
\hline Crude mortality rate & $0.000-1.3728$ & 0.0015 & 0.0059 \\
\hline \multicolumn{4}{|l|}{ Crude Infection rate } \\
\hline $0-500$ & & 120 & 75.9 \\
\hline $1000-1500$ & & 9 & 5.7 \\
\hline $1500-2000$ & & 5 & 3.2 \\
\hline $2000-2500$ & & 2 & 1.3 \\
\hline$>2500$ & & 8 & 5.1 \\
\hline
\end{tabular}

of COVID-19 in the world was examined in linear regression analysis. The comparison of dietary factors in countries with different infection rates was presented in Box Plots and examined in ANOVA-One way. The significant level of difference was determined in a P-value of less than 0.05 . The statistical analyses were performed by statistical package for social sciences version 25 (IBM SPSS Statistics for Windows, Version 25.0. Armonk, NY: IBM Corp).

\section{Ethical perspectives}

No ethical aspect was applicable to this study.

\section{Results}

The median crude infection rate by COVID-19 was 87.78 (IQR: 468.03) ranged between 0.00 and 24034.51 per 1000,000 persons. The median mortality rate by COVID-19 was 0.0015 (IQR: 0.0059 ) ranged between 0.00 and 1.3728 per 1000,000 persons. The two highest percentage of the crude infection rate were between 0 and 500 (75.9\%) and 500-1000 (8.9\%) per one million persons (Table 1).

The study showed the crude infection rate was raised with increasing consuming fruits $(\mathrm{r}=0.416 ; \mathrm{P}<0.001)$, unprocessed red meats $(\mathrm{r}=0.457 ; \mathrm{P}<0.001)$, fruit juices $(\mathrm{r}=0.390 ; \mathrm{P}<0.001)$, total protein $(\mathrm{r}=0.275 ; \mathrm{P}<0.001)$, calcium $(\mathrm{r}=0.550 ; \mathrm{P}<0.001)$, potassium $(\mathrm{r}=0.371, \mathrm{P}<0.001)$, and total milk $(\mathrm{r}=0.450$; $\mathrm{P}<0.001)$. Regarding crude mortality rate per 1000,000 persons; the study showed that crude mortality rate was raised with increasing consuming unprocessed red meats $(r=0.234$; $\mathrm{P}=0.007)$, sugar sweetened beverages $(\mathrm{r}=0.224 ; \mathrm{P}=0.010)$, fruit juices $(\mathrm{r}=0.272 ; \mathrm{P}=0.002)$, calcium $(\mathrm{r}=0.288 ; \mathrm{P}=0.001)$, and total milk $(\mathrm{r}=0.230 ; \mathrm{P}=0.008)$. However, the mortality rate was decreased following increasing consuming non-starchy vegetables $(\mathrm{r}=-0.196 ; \mathrm{P}=0.023)$, see Table 2 .

The regression analysis showed that the crude infection rate has been increased by raising consuming fruits (Beta: 0.237;
$\mathrm{P}=0.006$ ) and calcium (Beta: 0.286; $\mathrm{P}=0.007)$. However, the infection rate was decreased with rising consuming beans and legumes (Beta: $-0.145 ; \mathrm{P}=0.038$ ), Table 3 .

The effect of dietary factors on the crude mortality rate by COVID-19 was examined in the regression analysis. The analysis showed that the crude mortality rate was increased by raising consuming sugar-sweetened beverages (Beta: 0.340; $\mathrm{P}<0.001)$. Whereas, the crude mortality rate by COVID-19 has been decreased by increasing fruits consuming (Beta: -0.226; $\mathrm{P}=0.047$ ) and beans and legumes (Beta: $-0.176 ; \mathrm{P}=0.046$ ), as presented in Table 4.

The comparison of dietary factors in countries with different infection rates was examined in Table 5 and Fig 2. The study showed that the countries with higher infection rates between 1500 and above had a higher intake of fruits $(\mathrm{P}=0.002)$, fruit juices $(\mathrm{P}<0.001)$, calcium $(\mathrm{P}<0.001)$, potassium $(\mathrm{P}<0.001)$, and total milk $(\mathrm{P}<0.001)$. However, these countries had a lower intake of unprocessed red meats $(\mathrm{P}<0.001)$ and total protein $(\mathrm{P}=0.013)$.

\section{Discussion}

The aim of the food-based dietary guidelines is to maintain the general health of the population and prevent non-communicable diseases (14). Most of the food-based dietary guidelines recommend intake of whole grains, fruit and vegetables, low-fat dairy and fish, and low intake of red and processed meat, sugar-sweetened food products, alcohol, and salt (15).

The present study showed that the crude infection rate by COVID-19 has been increased by raising consuming fruits, calcium and decreased with increasing consuming beans and legumes. Regarding the mortality rate, the analysis showed that the crude mortality rate was increased by raising consuming sugar-sweetened beverages and decreased by increasing fruits consuming and beans and legumes.

The anti-inflammatory strategies inside foods, nutrients, or 
Table 2

Correlation of transformed infection and mortality rates of the COVID-19 with dietary factors in the world

\begin{tabular}{|c|c|c|c|c|c|c|c|c|c|c|c|}
\hline & \multicolumn{11}{|c|}{ Correlates Transformed infection rate $(\mathrm{N}=157)$} \\
\hline & Fruits & $\begin{array}{c}\text { Non-starchy } \\
\text { vegetables }\end{array}$ & $\begin{array}{l}\text { Beans and } \\
\text { legumes }\end{array}$ & $\begin{array}{l}\text { Nuts and } \\
\text { seeds }\end{array}$ & $\begin{array}{l}\text { Unprocessed } \\
\text { red meats }\end{array}$ & $\begin{array}{c}\text { Sugar-sweetened } \\
\text { beverages }\end{array}$ & Fruit juices & $\begin{array}{c}\text { Total } \\
\text { protein }\end{array}$ & Calcium & Potassium & $\begin{array}{l}\text { Total } \\
\text { milk }\end{array}$ \\
\hline Pearson Correlation & $0.416 * *$ & -0.044 & -0.149 & -0.106 & $0.457 * *$ & -0.052 & $0.390 * *$ & $0.275^{* *}$ & $0.550 * *$ & $0.371 * *$ & $0.450 * *$ \\
\hline \multirow[t]{2}{*}{ Sig. (2-tailed) } & $<0.001$ & 0.587 & 0.062 & 0.186 & $<0.001$ & 0.517 & $<0.001$ & $<0.001$ & $<0.001$ & $<0.001$ & $<0.001$ \\
\hline & \multicolumn{11}{|c|}{ Correlates Transformed mortality rate $(\mathrm{N}=\mathbf{1 3 3})$} \\
\hline Pearson Correlation & 0.032 & $-0.196^{*}$ & -0.128 & -0.004 & $0.234 * *$ & $0.224 * *$ & $0.272 * *$ & 0.145 & $0.288 * *$ & 0.030 & $0.230 * *$ \\
\hline Sig. (2-tailed) & 0.719 & 0.023 & 0.142 & 0.961 & 0.007 & 0.010 & 0.002 & 0.097 & 0.001 & 0.730 & 0.008 \\
\hline
\end{tabular}

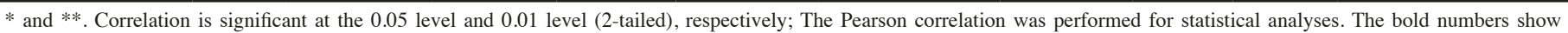
significant correlations with the infection rate; The units were $\mathrm{g} / \mathrm{d}$ for all except for calcium and potassium (mg/d).

Figure 1

Scatter plots of infection and mortality rates with dietary factors in the world

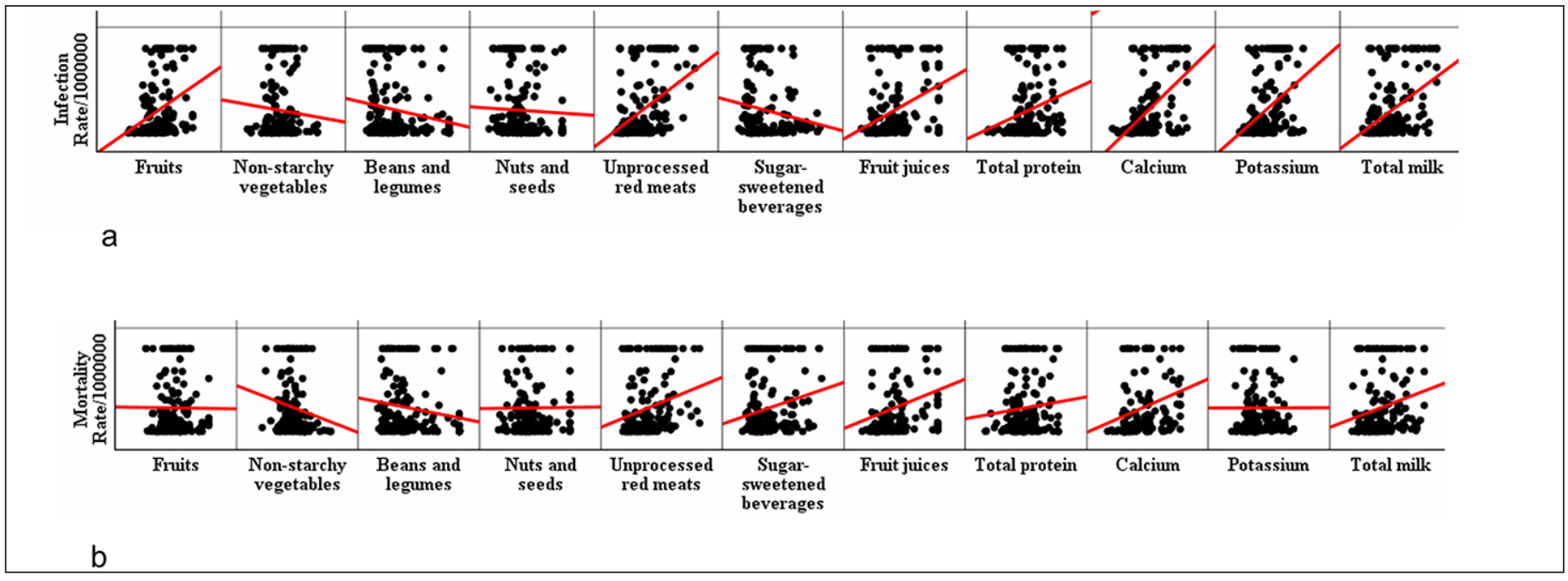

Table 3

Regression analysis of correlation of infection rate of COVID-19 with dietary factors in the world

Dietary factors $(n=158)$

Dependent variable: Crude infection rate of COVID-19 in the world

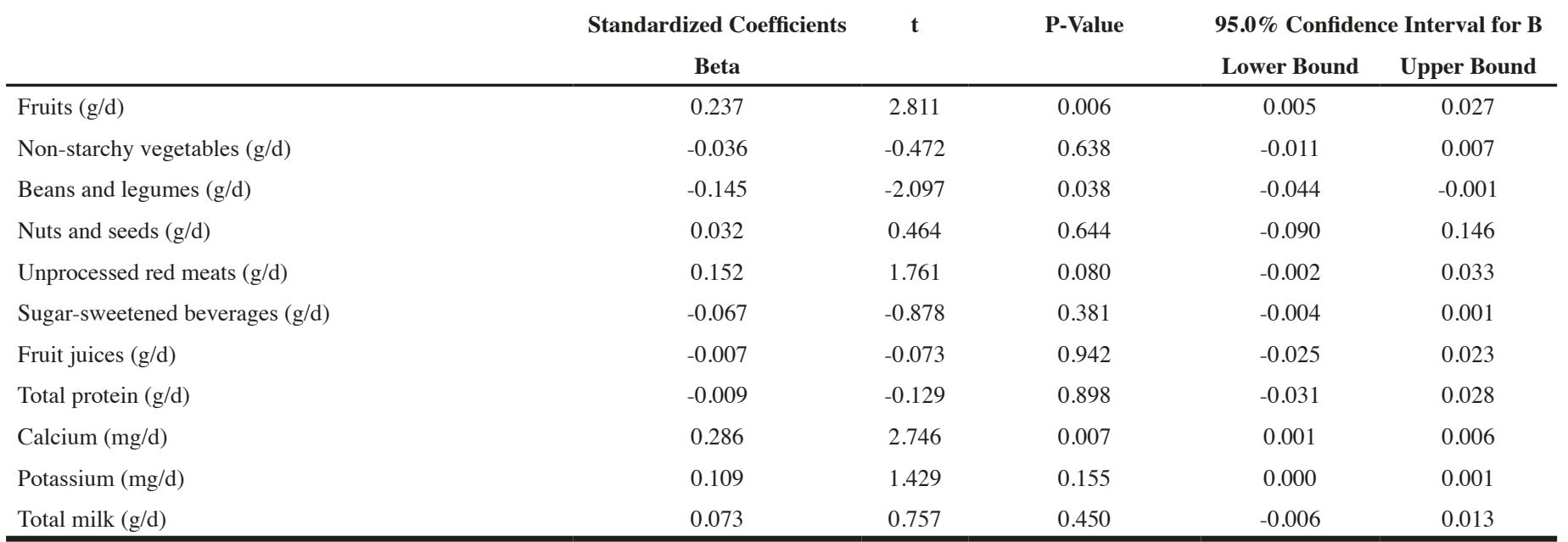

Linear regression was performed for statistical analysis. 
Figure 2

Comparison of dietary factors in countries with different infection rates
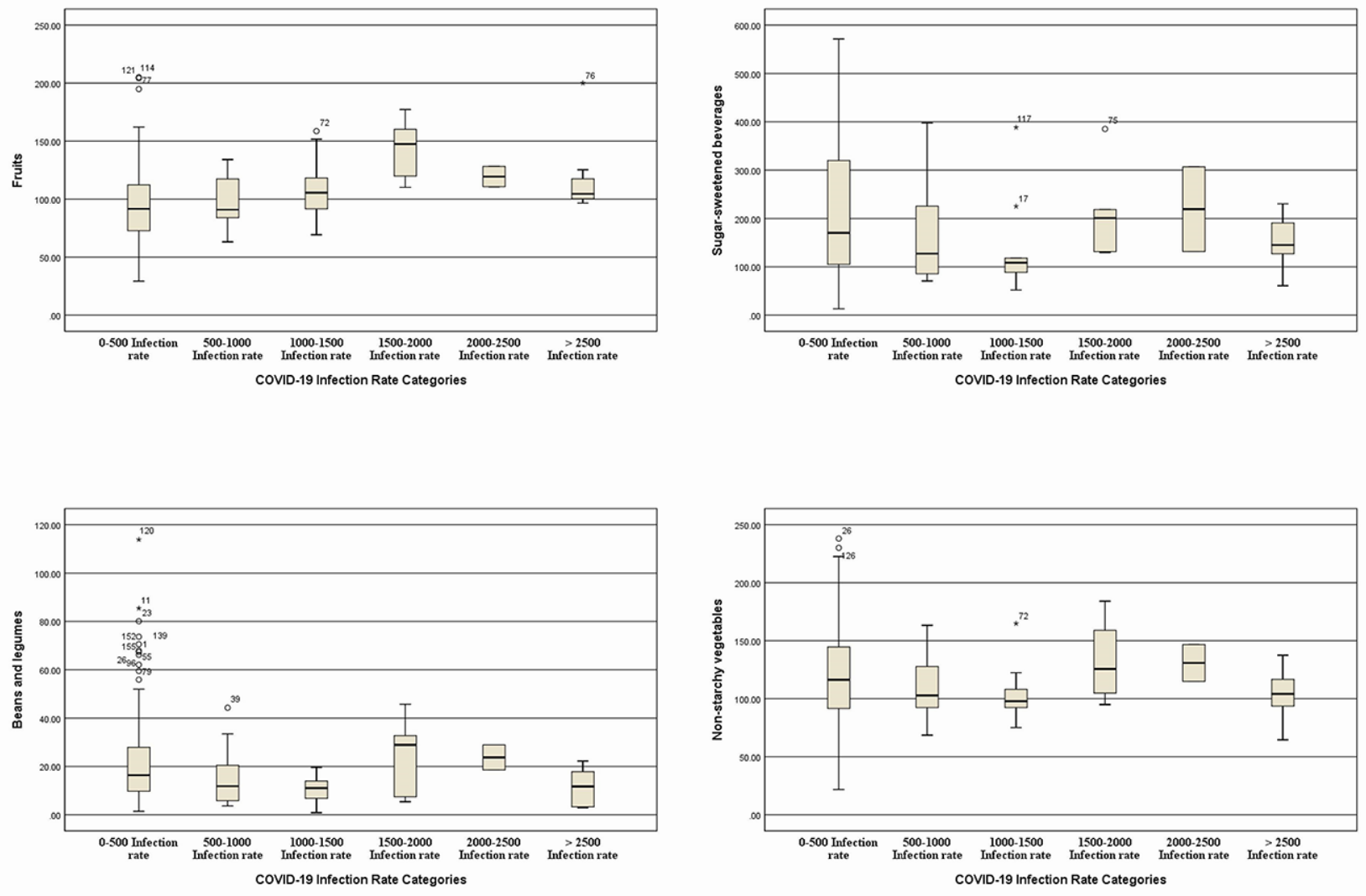

medicines are suggested as viable options for the management of COVID-19 $(16,17)$ since the coronavirus has serious inflammatory consequences for acute pneumonia in persons (18). The human coronavirus infections cause mild to severe diseases, systemic inflammation, high fever, cough, and acute respiratory tract infection and dysfunction in internal organs leading to death. This virus is classified as a RiboNucleic Acid (RNA) virus. The virus has a genome that often escapes the innate immune system, particularly if it is malfunctioning (19). Entering coronavirus into the organism activates innate immunity, which intervenes in the first instance to engulf the invader. The severity of the diseases locates within the ability of innate immune cells to stem viral infection (20). The virus has less ability to replicate itself and induce the pathological state in the case of the stronger innate immune system. When the immune system is suppressed by the virus, the body activates the adaptive immunity. The coronavirus enables to produce viral enzymes and proteases. These enzymes and proteases can damage the immunity and inhibit the signaling pathways of type I interferon (IFN) along with the nuclear factor- $x \mathrm{~B}$, facilitating innate immune evasion (21).

Apart from the age-related micronutrient inadequacy, the nutritional status of a person has a role in the developing risk of SARS- CoV- II infection, the clinical course, and the disease outcomes. Hence, the maintenance of host macro- and micronutrient status is considered to be a crucial preventive measure for COVID-19 (6).

The coronavirus infection is primarily attacked by immune cells, however, the virus has developed viral proteins overtime that counteracts with the innate immune system (22). Some of the viral proteins antagonize interferon (INF) and stimulate inflammatory proteins, such as IL-1 family member cytokines (23). The inflammatory state and pathogenesis of the disease are escalated after abnormal production of cytokines as shown in SARS (24).

Our hypothesis is that the higher intake of fruits makes the persons at further risk of infection by the COVID-19. Despite fruits and vegetables have anti-inflammatory and antioxidant factors and have an important role in enhancing the immune system responses (25). But higher intake of these micronutrients makes a barrier in improving the human immune system or response to the pathogens due to the role of the fruits with a high glycemic index. Our study showed that beans and legumes have a positive role in reducing the infection rate by the COVID-19. The human body requires the substates in the plant proteins to improve or respond to the vial pathogens because of the human body unable to produce these substrates (26). Therefore, the body needs these substates to protect the organs against the coronavirus. We assume that the immune body system unable to recognize the virus at the early times. 
Table 4

Regression analysis of correlation of mortality rate of COVID-19 with dietary factors with taking into account the infection rate in the world

\begin{tabular}{|c|c|c|c|c|c|}
\hline \multirow[t]{2}{*}{ Dietary factors and infection rate $(n=132)$} & \multirow{2}{*}{$\begin{array}{c}\text { Standardized Coefficients } \\
\text { Beta } \\
\end{array}$} & \multirow[t]{2}{*}{$\mathbf{t}$} & \multirow[t]{2}{*}{ P-Value } & \multicolumn{2}{|c|}{ 95.0\% Confidence Interval for B } \\
\hline & & & & Lower Bound & Upper Bound \\
\hline Fruits $(\mathrm{g} / \mathrm{d})$ & -0.226 & -2.011 & 0.047 & -0.021 & 0.000 \\
\hline Non-starchy vegetables (g/d) & -0.054 & -0.566 & 0.572 & -0.011 & 0.006 \\
\hline Beans and legumes $(\mathrm{g} / \mathrm{d})$ & -0.176 & -2.018 & 0.046 & -0.041 & 0.000 \\
\hline Nuts and seeds (g/d) & 0.038 & 0.444 & 0.658 & -0.078 & 0.124 \\
\hline Unprocessed red meats $(\mathrm{g} / \mathrm{d})$ & 0.182 & 1.631 & 0.105 & -0.003 & 0.028 \\
\hline Sugar-sweetened beverages (g/d) & 0.340 & 3.591 & $<0.001$ & 0.002 & 0.006 \\
\hline Fruit juices (g/d) & 0.065 & 0.566 & 0.573 & -0.015 & 0.026 \\
\hline Total protein $(\mathrm{g} / \mathrm{d})$ & 0.114 & 1.204 & 0.231 & -0.011 & 0.043 \\
\hline Calcium (mg/d) & 0.103 & 0.799 & 0.426 & -0.001 & 0.003 \\
\hline Potassium (mg/d) & -0.052 & -0.536 & 0.593 & -0.001 & 0.000 \\
\hline Total milk (g/d) & 0.045 & 0.376 & 0.708 & -0.007 & 0.010 \\
\hline Transformed Infection rate & 0.161 & 1.602 & 0.112 & -0.029 & 0.272 \\
\hline
\end{tabular}

Linear regression was performed for statistical analysis.

Therefore, the available proteins are essential for the body to make a response to the pathogen. The beans and legumes have been effective to reduce the rate of mortality by the COVID-19 as well.

The role of age in the suppression of the immune system must not be overlooked. The population of the countries with a higher infection rate is older compared to the counters with a low infection rate (27). For example, France and Italy compared to Iraq and Saudi Arabia. The available evidence indicates that adults aged 60 years and older and patients with preexisting medical conditions are more likely to have sever-even deadly- coronavirus infection that other population groups (28). Therefore, we can make the further hypothesis that the aged population of the countries with high infection rates has been the main factor in the low immune system. The impacts of aging on the immune system can reflect at multiple levels. The levels are decreased production of B and $\mathrm{T}$ cells in bone marrow and thymus and diminished functions of mature lymphocytes in secondary lymphoid tissues. So, the elderly persons do not respond to immune challenges as robustly as the young individual (29). The higher intake of fruits and vegetables may not be beneficial to enhance the immune system in aged populations. Diet alone may be insufficient and tailored micronutrient supplementation based on specific age-related needs necessary (7).

Many micronutrients are required for immune-competence, especially vitamin A, C, D, E, Bs, iron, selenium, and zinc. Moreover, the dietary pattern is essential to maintain the nutritional status of an individual. However, the diet alone could not be adequate in certain metabolic and lifestyle conditions, such as elderlies, co-existing medical conditions, cigarette smoking, or occupational exposure to environmental toxins (7). The fruits have several vitamins and minerals. The fruits at a ground level may not be quite suitable to make the final judgment.

The older persons over the age of 60-65 experience some immune dysregulation with less ability to respond to immune challenges and response to pathogens, antigens, and mitogens decreases (30). The decrease in the number of circulating lymphocytes and loss of immune cells are characteristics of the immune system in older people (31). Moreover, the older peoples have reduced the production of $T$ cells in the involved thymus and consequently diminished function of mature lymphocytes in secondary lymphoid tissues (29). The lifetime of exposure to antigens and to several sources of oxidative stress cause dysregulation in the immune system that makes them at further risk of infections than other age groups (31).

The role of fruits in enhancing immunity, such as micronutrients is in exhibiting pleiotropic roles in supporting immune function. The vitamins and minerals support to develop and maintain the physical barriers, produce and activate antimicrobial proteins (32). Some other mechanisms of micronutrients are supporting the growth, differentiation, and motility/chemotaxis of innate cells; phagocytic and killing activities of neutrophils and macrophages, and promotion of and recovery from inflammation (e.g. cytokine production and antioxidant activity (32).

The potential mechanisms of the fruits may back to the antiviral immune induction, the modulation of immunoregulatory defense, induction of autophagy and apoptosis, genetic or epigenetic regulation (33). Stimulation of defensins and cathelicidins may reduce the replication of the 
Table 5

Comparison of dietary factors among countries with different crude infection rates in the world

\begin{tabular}{|c|c|c|c|c|c|c|c|}
\hline \multirow[t]{2}{*}{ Dietary Factors $(\mathrm{n}=158)$} & \multicolumn{7}{|c|}{ Crude Infection Rate - Descriptive [Mean/Std. Deviation] } \\
\hline & $0-500$ & $500-1000$ & $1000-1500$ & $1500-2000$ & $2000-2500$ & $>2500$ & P-Value \\
\hline \multirow[t]{2}{*}{ Fruits $(\mathrm{g} / \mathrm{d})$} & 91.73 & 98.93 & 103.87 & 143.04 & 119.44 & 102.67 & 0.002 \\
\hline & 29.27 & 22.76 & 25.31 & 27.85 & 12.37 & 4.57 & \\
\hline Non-starchy vegetables (g/d) & 35.23 & 27.95 & 6.35 & 37.31 & 22.46 & 22.28 & 0.011 \\
\hline Beans and legumes $(\mathrm{g} / \mathrm{d})$ & 13.71 & 12.67 & 10.58 & 24.04 & 23.74 & 11.35 & \\
\hline & 1.62 & 2.03 & .61 & 9.00 & 2.79 & 4.07 & $<0.001$ \\
\hline \multirow[t]{2}{*}{ Unprocessed red meats $(\mathrm{g} / \mathrm{d})$} & 28.63 & 50.68 & 38.28 & 65.56 & 40.21 & 48.07 & \\
\hline & 16.09 & 28.92 & 19.37 & 27.67 & 44.82 & 15.78 & \\
\hline \multirow[t]{2}{*}{ Sugar-sweetened beverages $(\mathrm{g} / \mathrm{d})$} & 211.28 & 174.75 & 102.39 & 170.05 & 219.35 & 152.23 & 0.249 \\
\hline & 131.86 & 117.30 & 12.14 & 46.35 & 123.89 & 53.85 & \\
\hline \multirow[t]{2}{*}{ Calcium (mg/d) } & 601.08 & 820.49 & 723.07 & 874.89 & 780.08 & 942.52 & $<0.001$ \\
\hline & 129.70 & 202.45 & 165.51 & 178.54 & 126.91 & 98.67 & \\
\hline \multirow[t]{2}{*}{ Potassium (mg/d) } & 2168.25 & 2817.06 & 2762.38 & 3216.10 & 2715.37 & 2980.00 & $<0.001$ \\
\hline & 442.41 & 608.26 & 633.46 & 188.97 & 610.74 & 737.65 & \\
\hline \multirow[t]{2}{*}{ Total milk (g/d) } & 62.87 & 99.39 & 80.69 & 126.45 & 74.34 & 107.04 & $<0.001$ \\
\hline & 29.63 & 48.79 & 42.04 & 43.78 & 69.83 & 30.85 & \\
\hline
\end{tabular}

ANOVA-One Way was performed for statistical analyses; The bold numbers show a significant difference.

virus and raise the levels of anti-inflammatory cytokines, and reducing levels of pro-inflammatory cytokines (34). Here our hypothesis is that a higher intake of fruits suppresses the role of stimulation of defensins and cathelicidins.

The common denominator that reflects the role of nutrition and dietary recommendations against viral infections; including COVID-19 is the relation between diet and immunity (35). This is why we made our hypothesis based on the immunological effects of a higher intake of fruits in patients with COVID19 by taking into account the patients' ages. The evidence highlights that diet has an important effect on the immune system and disease vulnerability of peoples. The role of nutrients or nutrient combinations back to their effects on the immune system through the cell activation, modification in the production of signaling molecules, and gene expression (36).

The relation of fruits and beans and legumes on crude mortality rate is weak $(\mathrm{P}=0.047$ and $\mathrm{P}=0.046$, respectively) in contrast with the strong relation of sugar-sweetened beverages $(\mathrm{SSBs})(\mathrm{P}<0.001)$. The possible role of sugar-sweetened beverages on infection rate may back to its role in weight gain and the risk of obesity. A review study of observational and clinical trials showed that a higher intake of SSBs raised the risk of weight gain and obesity (37). The evidence has been confirmed elsewhere $(38,39)$. Accordingly, Maccioni et al. (40) recruited 1455 individuals aged $18-70$ in a cross-sectional study on airway infection in Germany. The study reported that obese persons have a consistently higher frequency of upper and lower respiratory tract infections (RTIs). The evidence has been reported elsewhere $(41,42)$. Obesity is responsible for the dysregulation of the immune system through mediation in different immune, metabolic, and thrombogenic responses (43). The higher intake of SSBs has been reported in high-income countries (44).

The effect of higher calcium intake on raising infection rates could be due to the effect of calcium on the risk of some other chronic diseases rather than its direct effect. A meta-analysis showed the increased incidence of myocardial infarction in persons who consume higher levels of calcium with a pooled relative risk of $1.27,95 \%$ confidence interval 1.01 to 1.59 , $\mathrm{P}=0.038$ (45). In addition, calcium has been reported as a trigger for ischemic cell death (46).

\section{Limitations of the study}

The daily recommended allowance/intake of the dietary factors are different across the countries. It is required to mention that food intake varies markedly based on the sociodemographic factors; like age gender, and educational level. We did not make stratification the results of the study based on the socio-demographic aspects since the WHO has not published the COVID-19 confirmed cases according to age, gender, and educational level. Besides, the cross-country caparison of individual-level dietary data is challenged by the dietary 


\section{DIETARY FACTORS IN COVID-19}

surveys performed with various survey characteristics and data collection methods with a possible influence in the comparison of the results. However, we used the FAO dietary data that represent the nationally representative sample of all age-sex, and educational level categories.

\section{Conclusions}

The present study showed the higher intake of fruits and sugar-sweetened beverages had a positive effect on infection and mortally rates by COVID-19, respectively. In contrast, the higher intake of beans and legumes had a negative effect on both increasing infection and mortality rates. The possible reason for the role of fruits and sugar-sweetened beverages on infection and mortally rates back to the indirect effect of weight gain and obesity and the role of age.

Conflicts of interest: The authors do not declare any conflicts of ineptest.

\section{References}

1. Gakidou E, Afshin A, Abajobir AA, Abate KH, Abbafati C, Abbas KM, Abd-Allah F, Abdulle AM, Abera SF, Aboyans V. Global, regional, and national comparative risk assessment of 84 behavioural, environmental and occupational, and metabolic risks or clusters of risks, 1990-2016: a systematic analysis for the Global Burden of Disease Study 2016. The Lancet 2017;390 (10100):1345-1422

2. Traill WB, Mazzocchi M, Shankar B, Hallam D. Importance of government policies and other influences in transforming global diets. Nutrition reviews 2014;72 (9):591604

3. Scott P. Global panel on agriculture and food systems for nutrition: food systems and diets: facing the challenges of the 21st century. Springer, 2017

4. Mertens E, Kuijsten A, Dofková M, Mistura L, D’Addezio L, Turrini A, Dubuisson C, Favret S, Havard S, Trolle E. Geographic and socioeconomic diversity of food and nutrient intakes: A comparison of four European countries. European journal of nutrition 2019;58 (4):1475-1493

5. de Boer J, Schösler H, Aiking H. "Meatless days" or "less but better"? Exploring strategies to adapt Western meat consumption to health and sustainability challenges. Appetite 2014;76:120-128

6. Gasmi A, Noor S, Tippairote T, Dadar M, Menzel A, Bjørklund G. Individual risk management strategy and potential therapeutic options for the COVID-19 pandemic Clinical Immunology 2020;108409

7. Maggini S, Pierre A, Calder PC. Immune function and micronutrient requirements change over the life course. Nutrients 2018;10 (10):1531

8. Calder PC, Carr AC, Gombart AF, Eggersdorfer M. Optimal nutritional status for a well-functioning immune system is an important factor to protect against viral infection, 2020s.

9. Zhang L, Liu Y. Potential interventions for novel coronavirus in China: a systemic review. Journal of medical virology, 2020

10. Gleeson M, Nieman DC, Pedersen BK. Exercise, nutrition and immune function. Journal of sports sciences 2004;22 (1):115-125

11. Global Dietary Database. The GDD 2015 Beta-Version Global Dietary Database. https://www.globaldietarydatabase.org/gdd-2015-beta-version, 2019.

12. World Health Organization, 2020. Coronavirus (COVID-19). World Health Organization. https://who.sprinklr.com/.

13. United Nations, 2020. Population by sex and urban/rural residence. United Nations Statistics Division. http://data.un.org/Data.aspx?d=POP\&f=tableCode\%3a1.

14. Mozaffarian D, Ludwig DS. Dietary guidelines in the 21 st century - a time for food Jama 2010;304 (6):681-682

15. WHO, 2003.Food-based Dietary Guidelines in the WHO European Region. WHO Regional Office for Europe Copenhagen,

16. Kritas S, Ronconi G, Caraffa A, Gallenga C, Ross R, Conti P. Mast cells contribute to coronavirus-induced inflammation: new anti-inflammatory strategy. J Biol Regul Homeostat Agents 2020;34 (1)

17. Conti P, Ronconi G, Caraffa A, Gallenga C, Ross R, Frydas I, Kritas S. Induction of pro-inflammatory cytokines (IL-1 and IL-6) and lung inflammation by Coronavirus-19 (COVI-19 or SARS-CoV-2): anti-inflammatory strategies. Journal of biological regulators and homeostatic agents 2020;34 (2)

18. Shi Y, Wang Y, Shao C, Huang J, Gan J, Huang X, Bucci E, Piacentini M, Ippolito G, Melino G. COVID-19 infection: the perspectives on immune responses. Nature
Publishing Group, 2020

19. Phan LT, Nguyen TV, Luong QC, Nguyen TV, Nguyen HT, Le HQ, Nguyen TT, Cao TM, Pham QD. Importation and human-to-human transmission of a novel coronavirus in Vietnam. New England Journal of Medicine 32020;82 (9):872-874

20. Zhu N, Zhang D, Wang W, Li X, Yang B, Song J, Zhao X, Huang B, Shi W, Lu R. A novel coronavirus from patients with pneumonia in China, 2019. New England Journal of Medicine, 2020.

21. Shokri S, Mahmoudvand S, Taherkhani R, Farshadpour F. Modulation of the immune response by Middle East respiratory syndrome coronavirus. Journal of cellular physiology 2019;234 (3):2143-2151

22. Oh M-d, Park WB, Choe PG, Choi S-J, Kim J-I, Chae J, Park SS, Kim E-C, Oh HS Kim EJ. Viral load kinetics of MERS coronavirus infection. New England Journal of Medicine 2016;375 (13):1303-1305

23. Li G, Fan Y, Lai Y, Han T, Li Z, Zhou P, Pan P, Wang W, Hu D, Liu X. Coronaviru infections and immune responses. Journal of medical virology 2020;92 (4):424-432

24. Doki T, Tarusawa T, Hohdatsu T, Takano T. In Vivo Antiviral Effects of U18666A Against Type I Feline Infectious Peritonitis Virus. Pathogens 2020;9 (1):67

25. Hosseini B, Berthon BS, Saedisomeolia A, Starkey MR, Collison A, Wark PA, Wood LG. Effects of fruit and vegetable consumption on inflammatory biomarkers and immune cell populations: a systematic literature review and meta-analysis. The American Journal of Clinical Nutrition 2018;108 (1):136-155

26. Li P, Yin Y-L, Li D, Kim SW, Wu G. Amino acids and immune function. British Journal of Nutrition 2007;98 (2):237-252

27. Ofori-Asenso R, Chin KL, Curtis AJ, Zomer E, Zoungas S, Liew D. Recent patterns of multimorbidity among older adults in high-income countries. Population health management 2019;22 (2):127-137

28. World Health Organization. Coronavirus disease 2019 (COVID-19): situation report, 2020;72.

29. Montecino-Rodriguez E, Berent-Maoz B, Dorshkind K . Causes, consequences, and reversal of immune system aging. The Journal of clinical investigation 2013;123 (3):958-965

30. Chandra RK. Nutrition and the immune system from birth to old age. European journal of clinical nutrition 2002;56 (3):S73-S76

31. Brodin P, Davis MM. Human immune system variation. Nature reviews immunology 2017;17 (1):21

32. Gombart AF, Pierre A, Maggini S. A Review of Micronutrients and the Immune System-Working in Harmony to Reduce the Risk of Infection. Nutrients 12 (1):236

33. Teymoori-Rad M, Shokri F, Salimi V, Marashi SM. The interplay between vitamin D and viral infections. Reviews in medical virology 2019;29 (2):e2032

34. Grant WB, Lahore H, McDonnell SL, Baggerly CA, French CB, Aliano JL, Bhattoa HP. Vitamin D supplementation could prevent and treat influenza, coronavirus, and pneumonia infections, 2020

35. Naja F, Hamadeh R. Nutrition amid the COVID-19 pandemic: a multi-level framework for action. European Journal of Clinical Nutrition2020;1-5

36. Valdés-Ramos R, Martínez-Carrillo BE, Aranda-González II, Guadarrama AL, PardoMorales RV, Tlatempa P, Jarillo-Luna RA. Diet, exercise and gut mucosal immunity. Proceedings of the Nutrition Society 2010;69 (4):644-650

37. Pereira MA. Sugar-sweetened and artificially-sweetened beverages in relation to obesity risk. Advances in nutrition 2014;5 (6):797-808

38. Malik VS, Schulze MB, Hu FB. Intake of sugar-sweetened beverages and weight gain: a systematic review-. The American journal of clinical nutrition 2006;84 (2):274-288

39. Vartanian LR, Schwartz MB, Brownell KD. Effects of soft drink consumption on nutrition and health: a systematic review and meta-analysis. American journal of public health 2007;97 (4):667-675

40. Maccioni L, Weber S, Elgizouli M, Stoehlker A-S, Geist I, Peter H-H, Vach W, Nieters A. Obesity and risk of respiratory tract infections: results of an infection-diary based cohort study. BMC public health 2018;18 (1):271

41. Falagas ME, Kompoti M. Obesity and infection. The Lancet infectious diseases 2006;6 (7):438-446

42. Karlsson EA, Beck MA. The burden of obesity on infectious disease. Experimental biology and medicine 2010;235 (12):1412-1424

43. Fernandez C, Manuel A. Obesity, respiratory disease and pulmonary infections. Ann Res Hosp 2017;38 (1):1-9

44. Singh GM, Micha R, Khatibzadeh S, Shi P, Lim S, Andrews KG, Engell RE, Ezzat M, Mozaffarian D, Nutrition GBoD, Group CDE. Global, regional, and national consumption of sugar-sweetened beverages, fruit juices, and milk: a systematic assessment of beverage intake in 187 countries. PloS one 2015;10 (8)

45. Bolland MJ, Avenell A, Baron JA, Grey A, MacLennan GS, Gamble GD, Reid IR Effect of calcium supplements on risk of myocardial infarction and cardiovascular events: meta-analysis. Bmj 2010;341:c3691

46. Kristián T, Siesjö BK. Calcium in ischemic cell death. Stroke 1998;29 (3):705-718 